\title{
Hard Turning of HSLA Steel with Coated Ceramic Inserts: An Assessment, Modelling, Optimisation and Cost Analysis
}

\author{
A. Panda, S. R. Das* and D. Dhupal \\ Department of Production Engineering, Veer Surendra Sai University gf Technology, \\ 768018 Burla, Odisha, India \\ *Email: das.sudhansu83@ gmail.com \\ Phone: +919937347205 \\ ABSTRACT
}

The present study addresses the machinability investigation in finish dry hard turning of high strength low alloy (HSLA) steel with coated ceramic inserts by considering cutting speed, feed and depth of cut as machining parameters. The technological parameters like surface roughness, flank wear, and economic analysis have been considered to investigate machinability performances. Twenty-seven set of trials according to full factorial design of experiments are conducted, and subsequently, analysis of variance, multiple regression method, Taguchi method, desirability funetion approach and finally Gilbert's technique is employed for parametric influence study, mathematical modelling, multi-response optimisation, tool life estimation and economic analysis. Novelty aspects, the current work demonstrates the substitytion of conventional, expensive and slow cylindrical grinding process, and proposes the most expensive CBN tool alternative using coated ceramic tools in hard turning process considering techno-economic and ecological aspects, which they are useful and efficient from the industrial point of views.

Keywords: Machinability, hard turning, AISI 4340 steel, coated ceramic, economic analysis.

Retraction Notice:

IJAME editorial team takes integrity matters seriously and would not allow any manipulation of scientific articles. We would like to apologise to IJAME readers for any inconvenience caused by this retraction. Please contact the editor in chief for more info. 